\title{
əThe Effect of Wind Stress on Seasonal Sea-Level Change on the Northwestern European Shelf $\mathscr{0}$
}

\author{
Tim H. J. Hermans, ${ }^{\mathrm{a}, \mathrm{b}}$ CARoline A. Katsman, ${ }^{\mathrm{c}}$ CARolina M. L. CAmargo, ${ }^{\mathrm{a}, \mathrm{b}}$ Gregory G. Garner, ${ }^{\mathrm{d}, \mathrm{e}}$ \\ Robert E. Kopp, ${ }^{\text {de }}$ AND AimÉE B. A. Slangen ${ }^{a}$ \\ ${ }^{a}$ Department of Estuarine and Delta Systems, Royal Netherlands Institute for Sea Research (NIOZ), Yerseke, Netherlands \\ ${ }^{\mathrm{b}}$ Department of Geosciences and Remote Sensing, Delft University of Technology, Delft, Netherlands \\ ${ }^{\mathrm{c}}$ Department of Hydraulic Engineering, Delft University of Technology, Delft, Netherlands \\ ${ }^{\mathrm{d}}$ Department of Earth and Planetary Sciences, Rutgers, The State University of New Jersey, Piscataway, New Jersey \\ ${ }^{\mathrm{e}}$ Rutgers Institute of Earth, Ocean, and Atmospheric Sciences, Rutgers, The State University of New Jersey, New Brunswick, New Jersey
}

(Manuscript received 17 August 2021, in final form 19 December 2021)

\begin{abstract}
Projections of relative sea level change (RSLC) are commonly reported at an annual mean basis. The seasonality of RSLC is often not considered, even though it may modulate the impacts of annual mean RSLC. Here, we study seasonal differences in twenty-first-century ocean dynamic sea level change (DSLC; 2081-2100 minus 1995-2014) on the Northwestern European Shelf (NWES) and their drivers, using an ensemble of 33 CMIP6 models complemented with experiments performed with a regional ocean model. For the high-end emissions scenario SSP5-8.5, we find substantial seasonal differences in ensemble mean DSLC, especially in the southeastern North Sea. For example, at Esbjerg (Denmark), winter mean DSLC is on average $8.4 \mathrm{~cm}$ higher than summer mean DSLC. Along all coasts on the NWES, DSLC is higher in winter and spring than in summer and autumn. For the low-end emissions scenario SSP1-2.6, these seasonal differences are smaller. Our experiments indicate that the changes in winter and summer sea level anomalies are mainly driven by regional changes in wind stress anomalies, which are generally southwesterly and east-northeasterly over the NWES, respectively. In spring and autumn, regional wind stress changes play a smaller role. We also show that CMIP6 models not resolving currents through the English Channel cannot accurately simulate the effect of seasonal wind stress changes on the NWES. Our results imply that using projections of annual mean RSLC may underestimate the projected changes in extreme coastal sea levels in spring and winter. Additionally, changes in the seasonal sea level cycle may affect groundwater dynamics and the inundation characteristics of intertidal ecosystems.
\end{abstract}

KEYWORDS: Wind stress; Sea level; Climate change; Climate models; Ocean models; Seasonal cycle; Seasonal effects; Wind effects

\section{Introduction}

Probabilistic regional sea level projections are crucial for coastal adaptation planning (e.g., Hinkel et al. 2019). New sea level projections are continuously being developed for a range of emissions scenarios, building on the latest understanding of the physical processes contributing to relative sea level change (RSLC) (Fox-Kemper et al. 2021 and references therein). Most of these projections focus on annual mean RSLC. However, the seasonal sea level cycle may also change over time, which has the potential to modulate the impacts of RSLC in particular seasons.

Widlansky et al. (2020) recently showed that seasonal sea level variability will increase in many regions in which the ocean warms. The authors argue that this is at least partially

Supplemental information related to this paper is available at the Journals Online website: https://doi.org/10.1175/JCLI-D-210636.s1.

○Denotes content that is immediately available upon publication as open access.

Corresponding author: Tim H. J. Hermans, tim.hermans@nioz.nl because of the larger thermal expansion of the ocean at higher temperatures, which implies that steric sea level variability will increase even if the temperature variability stays constant. In shallow coastal regions, however, barotropic processes also contribute substantially to the seasonal sea level cycle (Roberts et al. 2016; Vinogradov et al. 2008; Vinogradova et al. 2007). The effect of barotropic processes on future changes of the seasonal sea level cycle in coastal regions has not been extensively studied yet.

This study focuses on seasonal changes in the coastal region northwest of Europe. The Northwestern European Shelf (NWES) harbors shallow shelf seas, such as the North Sea, with low-lying and densely populated coasts. On the NWES, atmospheric forcing is the dominant driver of the interannual variability of annual mean sea level (Dangendorf et al. 2014a; Hermans et al. 2020a; Tinker et al. 2020). Atmospheric forcing also affects the temporal variability of the seasonal sea level cycle on the NWES (Plag and Tsimplis 1999). The magnitude of the interannual to multidecadal variability of seasonal mean sea level and the extent to which that variability can be explained by atmospheric forcing are larger for autumn and winter than for spring and summer (Dangendorf et al. 2012, 2013a; Frederikse and Gerkema 2018). For example, a regression on local wind stress explains $80 \%-90 \%$ of the observed interannual sea level variability at Cuxhaven (Germany) in 
autumn and winter, compared to $50 \%-60 \%$ in spring and summer (Dangendorf et al. 2013a). This reflects the seasonality of atmospheric variability and introduces seasonal differences in sea level trends computed over a few decades, especially in the southeastern North Sea (Dangendorf et al. 2012, 2013b; Frederikse and Gerkema 2018; Marcos and Tsimplis 2007).

At centennial time scales, seasonal differences in RSLC on the NWES have also been observed. For example, along the Dutch coast, Gerkema and Duran-Matute (2017) found differences of $0.35-0.81 \mathrm{~mm} \mathrm{yr}^{-1}$ between 100 -yr trends of sea level in winter and summer half-years. Also in the Baltic Sea, seasonal differences in RSLC of several centimeters were observed (Ekman 1998). These were linked to seasonal differences in the change of southwesterly winds over the entrance to the Baltic Sea. Although these findings suggest that RSLC may also have seasonal differences in the future, only a few studies have investigated the seasonality of sea level projections for the NWES (Dangendorf et al. 2014b; Hermans et al. 2020b; Mathis 2013). Moreover, the results of these studies were based on a limited number of models and/or were obtained for only a part of the NWES.

Here, we explore the seasonal differences in ocean dynamic sea level change (DSLC) over the twenty-first century as simulated by a large ensemble of state-of-the-art global climate models from phase 6 of the Coupled Model Intercomparison Project (CMIP6; Eyring et al. 2016). Additionally, we investigate if these seasonal differences can be attributed to the projected wind stress changes over the region. To better understand the effect of wind stress changes, we complement the CMIP6 simulations with experiments performed with a high-resolution regional ocean model for the NWES (Hermans et al. 2020a). Section 2 describes both these datasets. Section 3 shows that, depending on the emissions scenario, CMIP6 models simulate substantial seasonal differences in DSLC. In section 4, we present seasonal differences in ensemble-mean wind stress change and test the effect of wind stress changes on sea level in individual CMIP6 models using the regional model. We also study the importance of the representation of the English Channel. We end with a discussion and our conclusions in section 5 .

\section{CMIP6 simulations and regional ocean model experiments}

Section 2a details how we obtained and processed the CMIP6 output. In section 2b, we introduce the high-resolution regional ocean model and the experiments that we performed with it.

\section{a. Downloading and processing the CMIP6 output}

We use simulations of dynamic sea level and wind stress from an ensemble of 33 CMIP6 models (see the overview in supplemental Table 1 in the online supplemental material), downloaded from the Earth System Grid Federation database in July 2021. The variables used are monthly mean dynamic sea level above the geoid (called "zos") and the zonal and meridional wind stress components at the surface ("tauu" and "tauv"). Since we use zos, we study DSLC as defined by Gregory et al. (2019) and therefore exclude the inverse barometer effect (Stammer and Huttemann 2008).

All simulation realizations that provide both sea level and wind stress for the historical period and the high-end shared socioeconomic pathway scenario SSP5-8.5 (O'Neill et al. 2014) are used. For sea level, we also obtain the same realizations for the low-end emissions scenario SSP1-2.6, if available. We focus on the output for the SSP5-8.5 scenario, since it has the highest signal-to-noise ratio. To indicate the range within which seasonal differences in DSLC for other SSPs may fall, we present results for the SSP1-2.6 scenario in the online supplemental material. Additionally, we download preindustrial control simulations of zos, which are required to correct DSLC for ocean model drift. Finally, for our regional model experiments (section $2 \mathrm{~b}$ ), we also download the wind velocity components at a height of $10 \mathrm{~m}$ (called "uas" and "vas") for a subset of CMIP6 models.

The CMIP6 zos output first needs to be corrected for ocean model drift (Sen Gupta et al. 2013). We do so by applying a linear fit to zos over the full length of the preindustrial control run of each model and by subtracting these fits from the historical and SSP runs. This commonly used procedure implicitly assumes that the model drift and the forced changes are linearly separable (Hobbs et al. 2016; Sen Gupta et al. 2013). Since zos is defined as sea level above the geoid, and the geoid is time-invariant in CMIP6 models, we also remove the global area-weighted mean of zos at each time step using the grid cell area information (called "areacello"). For the analysis of gridded ensemble projections (e.g., Figs. 1 and 3), we bilinearly interpolate the CMIP6 simulations to a common $1^{\circ} \times 1^{\circ}$ grid using ESMValTool routines (Eyring et al. 2020).

Before adding each model to the multimodel ensemble, we first take the mean of all available realizations of each model, following Yin (2012). Since each realization of a simulation of a given model is branched from its preindustrial control run at a different time, the phase of the internal sea level variability differs between each realization. Averaging over the available realizations reduces the effect of internal sea level variability on the projections of each model, leading to a better representation of the externally forced response. In section 5, we will show that this moderately reduces the multimodel ensemble spread. Projections derived from models with relatively few realizations will be affected by internal variability the most. However, using only models with an equal number of multiple realizations would substantially reduce the ensemble size. Supplemental Table 1 provides an overview of the CMIP6 output that we used. We exclude simulations that do not provide the complete (meta)data required for the processing steps described above. Additionally, we exclude the models MIROC6 and MIROCES2L, because their minimum ocean depth on the NWES is $150 \mathrm{~m}$. This is unrealistically deep compared to the other CMIP6 models (10-60 m). At 90 and $193 \mathrm{~km}$, the average native ocean and atmosphere grid resolution of the CMIP6 models in the NWES region is relatively coarse (supplemental Table 1), but large ensembles of high-resolution models are currently not available. 
From the processed monthly mean CMIP6 output, we compute seasonal means by averaging over December-February (DJF), March-May (MAM), June-August (JJA), and September-November (SON). To study the seasonal differences in DSLC, we then compute seasonal anomalies by subtracting the annual mean of each year from the seasonal means of that year, with the annual mean calculated over December to November. We abbreviate the seasonal anomalies of sea level, wind stress, and wind velocity as SSLA, SWSA, and SWVA, respectively. We compute the projected change of these anomalies ( $\triangle$ SSLA, $\Delta$ SWSA, and $\Delta$ SWVA) from the difference between the future mean (2081-2100) and the historical mean (1995-2014) anomalies.

\section{b. Regional ocean model and model experiments}

To test the effect of wind stress changes in CMIP6 models on sea level (sections $4 \mathrm{~b}$ and $4 \mathrm{c}$ ), we perform experiments with a regional ocean model for the NWES (Hermans et al. 2020a). This model is a configuration of the Regional Ocean Modeling System (ROMS; Shchepetkin and McWillams 2005) and covers the region $36^{\circ}-62^{\circ} \mathrm{N}, 20^{\circ} \mathrm{W}-10^{\circ} \mathrm{E}$ with a $1 / 8^{\circ}$ by $1 / 8^{\circ}$ horizontal resolution. At the surface and lateral boundaries, the ROMS model is forced with atmosphere (ERA5; CDS 2019) and ocean reanalysis data [Global Ocean Reanalysis and Simulation, stream 12, version 1 (GLORYS12v1); Lellouche et al. 2018]. Climatological river runoff is prescribed based on the dataset of Dai (2017). Simulations with this model compare well with satellite altimetry data and were used to study the drivers of interannual sea level variability on the NWES (Hermans et al. 2020a).

Here, the reanalysis-forced model simulation is our reference experiment. For our sensitivity experiments (Table 1), we add the $\triangle$ SWVA derived from four example CMIP6 models (for SSP5-8.5) to the wind velocity boundary conditions from ERA5 at each time step. We compute the resulting response of sea level and barotropic currents for a specific season as the difference relative to the reference experiment, averaged over 1993-95. We use three CMIP6 models that span a wide range of $\triangle$ SSLA and provide at least five realizations each: CanESM5, UKESM1-0-LL, and IPSL-CM6A-LR. Additionally, we use a model with a closed English Channel: ACCESS-ESM1-5. For further interpretation, we also simulate the effect of spatially uniform southwesterly and northeasterly wind velocity changes. To test the importance of the representation of the English Channel, we repeat several experiments using a modified land mask in which the English Channel is closed at the Strait of Dover (Table 1).

To add the wind-velocity changes from the CMIP6 models to the surface boundary conditions, we bilinearly interpolate. To avoid prescribing the ROMS model with land-contaminated wind velocity changes (Kara et al. 2007), we first use nearest-neighbor extrapolation to replace the wind velocity change of (partially) overland grid cells with the wind velocity change of purely over-ocean grid cells in the CMIP6 models. We only extrapolate if it leads to larger wind velocity changes, because overland winds are weaker than over-ocean winds.
We emphasize that we only use the regional model experiments to qualitatively understand the effect of $\Delta$ SWSA on $\Delta$ SSLA and barotropic currents in the different CMIP6 models. Our model experiments are less well suited for a quantitative attribution because of the differences between the regional model and the global models, and because of the potential inconsistencies of combining coarse-resolution CMIP6 wind velocity changes with ERA5 atmospheric forcing. For instance, the wind velocity changes that we apply may not translate to exactly the same wind stress changes as in the CMIP6 models, since the climatological wind velocities and the parameterization of air-sea fluxes may differ between the ROMS setup and the CMIP6 models. Additionally, we ignore the results of the model experiments near Norway, because we do not modify the eastern lateral boundary conditions of the ROMS model that control the Norwegian Coastal Current.

\section{Seasonal DSLC in CMIP6 models}

In this section, we investigate seasonal differences in DSLC by analyzing $\Delta$ SSLA. First, we analyze CMIP6 projections of $\triangle$ SSLA on the NWES (section 3a). Then, we zoom in on sea level projections for Esbjerg (section 3b), which we find is a location on the NWES with large seasonal DSLC differences.

\section{a. $\triangle S S L A$ on the NWES}

Figures 1a-d show that for SSP5-8.5, the magnitude of the ensemble mean $\triangle$ SSLA reaches up to $4.9 \mathrm{~cm}$ on the NWES, which indicates how much seasonal mean DSLC may deviate from annual mean DSLC (supplemental Fig. 1a). In the Celtic and Irish Seas, in part of the English Channel, along parts of the coast of Ireland and Scotland, and in the southern and eastern North Sea, ensemble mean $\triangle$ SSLA is most positive (DSLC is highest) in winter (Fig. 1a). Elsewhere on the shelf, $\triangle$ SSLA is highest in spring (Fig. 1b). The spatial patterns of summer and autumn $\Delta$ SSLA (Figs. 1c,d) approximately oppose those of winter and spring (Figs. 1a,b). Whereas spring and autumn $\triangle$ SSLA are spatially relatively uniform, winter and summer $\triangle$ SSLA show a dipole pattern in the North Sea. Along the coast of the southeastern North Sea, the seasonal differences are largest. For example, at Esbjerg (Denmark), winter and summer $\Delta$ SSLA are 3.7 and $-4.7 \mathrm{~cm}$, respectively. Therefore, on average, the CMIP6 models simulate an $8.4 \mathrm{~cm}(52 \%)$ increase in the difference between winter and summer mean sea level for SSP5-8.5 (see supplemental Fig. 2 for historical and future SSLAs on the NWES).

The multimodel distributions of $\triangle$ SSLA (Fig. 1e) reveal that DSLC is larger in spring than in autumn at all eight example coastal locations on the NWES (Fig. 1e). However, especially at Den Helder, Cuxhaven, and Esbjerg (locations 6-8), the difference between winter and summer mean DSLC exceeds the difference between spring and autumn mean DSLC. Together, these changes shift the phase and increase the amplitude of the seasonal sea level cycle (supplemental Fig. 2i). Additionally, at locations 6-8, the intermodel spread introduces large uncertainty in the projections. Consequently, 
(a) Winter (DJF)

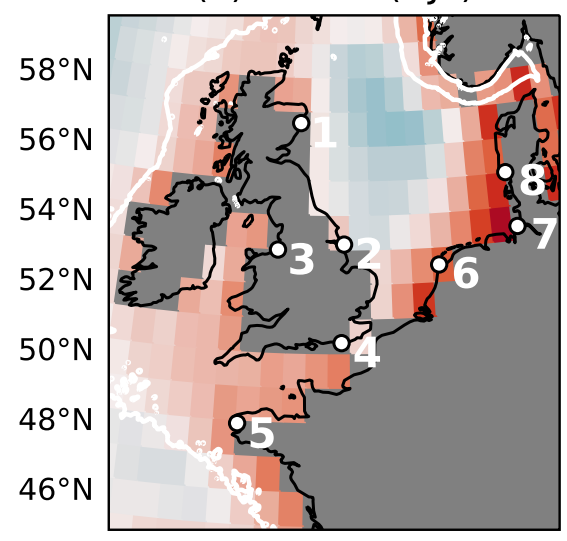

(c) Summer (JJA)
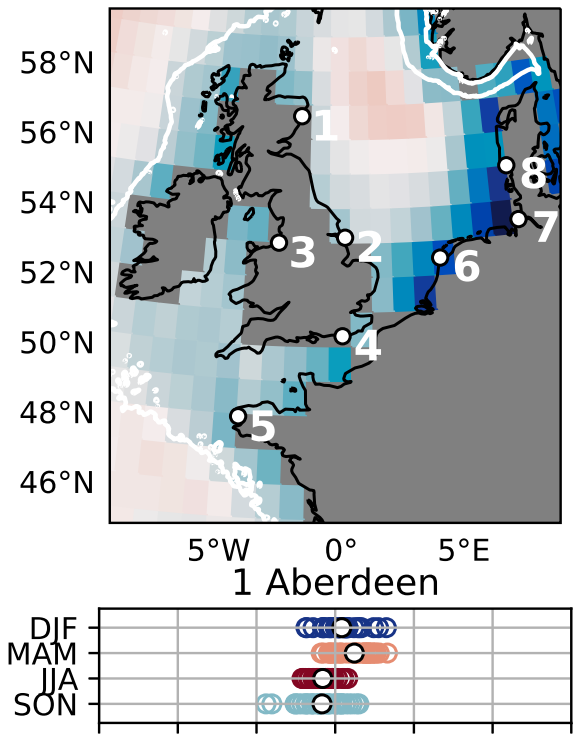

3 Liverpool

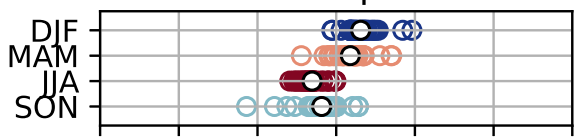

5 Brest

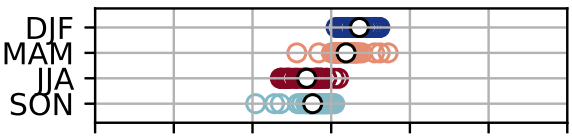

7 Cuxhaven

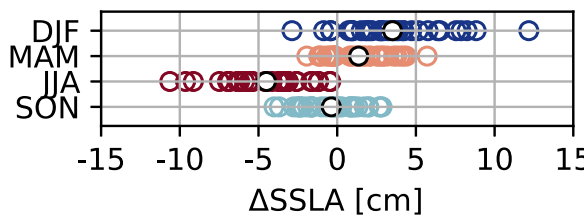

(b) Spring (MAM)

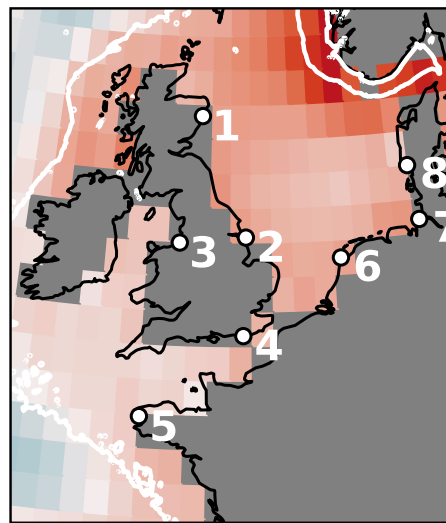

(d) Autumn (SON)

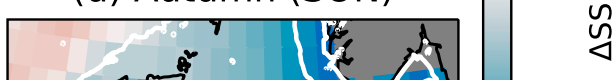

(e)
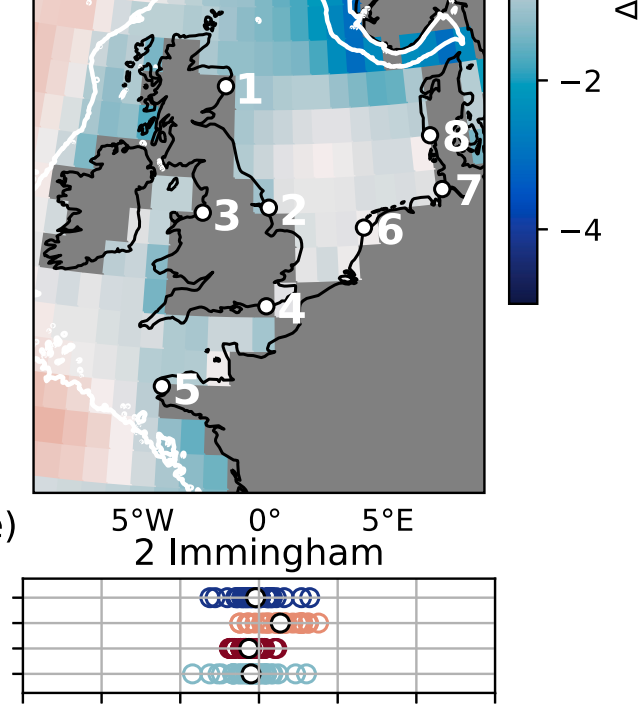

4 Newhaven

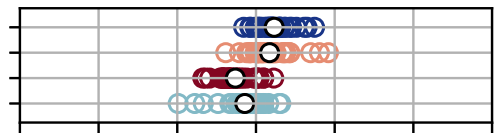

6 Den Helder

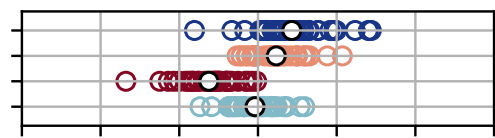

8 Esbjerg

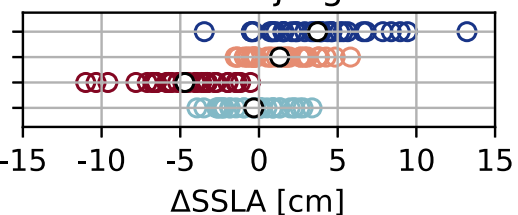

FIG. 1. Ensemble mean changes of (a) winter (DJF), (b) spring (MAM), (c) summer (JJA), and (d) autumn (SON) sea level anomalies (cm) for SSP5-8.5 (2081-2100 relative to 1995-2014), and (e) the multimodel distributions of these changes in CMIP6 models at their ocean grid cells nearest to eight example coastal locations. Each colored circle represents the change in one model; the black-edged circle represents the ensemble mean. In (a)-(d), ensemble-mean results are shown only on grid cells for which at least five CMIP6 models provide ocean values on a common $1^{\circ} \times 1^{\circ}$ grid. The white contour denotes the 200-m isobath from ETOPO1 (Amante and Eakins 2009) approximating the shelf break. 
TABLE 1. Model experiments discussed in sections $4 \mathrm{~b}$ and $4 \mathrm{c}$. The boundary conditions other than wind velocity are identical in all experiments.

\begin{tabular}{lcc}
\hline \hline Model experiments & Modification of ERA5-based wind velocity boundary conditions & English Channel \\
\hline Exp_Ref & - & Open \\
Exp_Ref_cc & - & Closed \\
Exp_CAN & $+\Delta$ SWVA from CanESM5 & Open \\
Exp_UK & $+\Delta$ SWVA from UKESM1-0-LL & Open \\
Exp_IPSL & $+\Delta$ SWVA from IPSL-CM6A-LR & Open \\
Exp_ACC & $+\Delta$ SWVA from ACCESS-ESM1-5 & Open \\
Exp_ACC_cc & $+\Delta$ SWVA from ACCESS-ESM1-5 & Closed \\
Exp_SW & $+1 \mathrm{~m} \mathrm{~s}^{-1}$ southerly and 1 m s $\mathrm{m}^{-1}$ westerly & Open \\
Exp_SW_cc & $+1 \mathrm{~m} \mathrm{~s}^{-1}$ southerly and $1 \mathrm{~m} \mathrm{~s}^{-1}$ westerly & Closed \\
Exp_NE & $+1 \mathrm{~m} \mathrm{~s}^{-1}$ northerly and $1 \mathrm{~m} \mathrm{~s}^{-1}$ easterly & Open \\
Exp_NE_cc & $+1 \mathrm{~m} \mathrm{~s}^{-1}$ northerly and $1 \mathrm{~m} \mathrm{~s}^{-1}$ easterly & Closed \\
\hline
\end{tabular}

studying the seasonality of DSLC is particularly relevant for the southeastern North Sea.

For the SSP1-2.6 scenario, the spatial patterns of $\Delta$ SSLA are comparable to those for the SSP5-8.5 scenario, but have a smaller magnitude (supplemental Fig. 3). For example, the ensemble mean winter and summer $\Delta$ SSLA at Esbjerg are 0.1 and $-1.0 \mathrm{~cm}$, compared to 3.7 and $-4.7 \mathrm{~cm}$ for SSP5-8.5. As for SSP5-8.5, the intermodel spread of $\triangle$ SSLA at locations 6-8 is larger than at the other locations. Since the signal-tonoise ratio is lower for SSP1-2.6, there is less agreement between models on the season of largest DSLC than for SSP5-8.5. In contrast to SSP5-8.5, DSLC for SSP1-2.6 is highest in spring and lowest in autumn on most of the NWES. Therefore, the projected seasonal differences in DSLC are scenario dependent.

\section{b. Seasonal sea level projections at Esbjerg}

The largest seasonal differences in DSLC occur in the southeastern North Sea, for example near Esbjerg (Fig. 1). We therefore illustrate the seasonality of sea level projections for Esbjerg in further detail. At Esbjerg, the CMIP6 ensemble has a median annual mean DSLC of $17.7 \mathrm{~cm}$ and a $5 \%-95 \%$ range of 2.2-26.1 cm for SSP5-8.5 (Fig. 2a, black bar). Spring and autumn mean DSLC have slightly higher and lower multimodel medians than annual mean DSLC (18.2 and $16.9 \mathrm{~cm})$, respectively, and have differently shaped distributions (Fig. 2a, light blue and light red bars). For winter, the ensemble projections are overall higher than for the annual mean, with a median of $21.1 \mathrm{~cm}$ and a $5 \%-95 \%$ range of $2.9-31.6 \mathrm{~cm}$ (Fig. 2a, dark blue bar). The projections for summer are substantially lower than for the annual mean, with a median of $11.1 \mathrm{~cm}$ and a $5 \%-95 \%$ range of $0.8-20.7 \mathrm{~cm}$ (Fig. 2a, dark red bar).

At Esbjerg, the changes in seasonal sea level anomalies are most apparent for winter and summer (Fig. 2b, dark blue and dark red bars). The CMIP6 ensemble projects a median win-

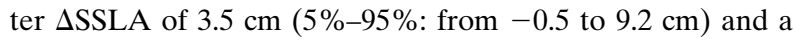
median summer $\Delta$ SSLA of $-4.1 \mathrm{~cm}(5 \%-95 \%$ : from -9.9 to $-1.3 \mathrm{~cm})$. The finding that the multimodel distributions of $\Delta$ SSLA are not equal to the difference between the distributions of seasonal and annual mean DSLC indicates that models that simulate large/small seasonal differences in DSLC do not necessarily also simulate large/small annual mean DSLC. As noted in section 3a, the seasonal differences in the projections for Esbjerg are much smaller for SSP1-2.6 than for SSP5-8.5 (supplemental Fig. 4).

The results in sections $3 \mathrm{a}$ and $3 \mathrm{~b}$ raise the question of what causes the scenario-dependent seasonality of DSLC. In section 4, we therefore study the dynamics behind the seasonal differences in DSLC on the NWES. We focus on the effect of wind stress, motivated by the high correlation between observed seasonal mean sea level and wind stress on interannual to multidecadal time scales (Dangendorf et al. 2013b, 2014b; Frederikse and Gerkema 2018; Plag and Tsimplis 1999).

\section{The effect of wind stress on seasonal differences in DSLC}

To study the effect of wind stress on seasonal differences in DSLC, we first investigate the ensemble mean changes in seasonal wind stress anomalies ( $\triangle$ SWSA) and discuss their relation to ensemble mean $\triangle$ SSLA (section 4a). Second, we compare $\triangle$ SSLA and $\triangle$ SWSA between individual CMIP6 models and test the effect of the wind stress changes in these models on sea level using high-resolution model experiments (section 4b). Finally, in section 4c, we use model experiments to test the impact of the representation of the English Channel in CMIP6 models on simulating wind-driven $\triangle$ SSLA.

\section{a. Ensemble mean $\triangle S W S A$ over the NWES}

In winter, the ensemble mean $\Delta$ SWSA for SSP5-8.5 is approximately southwesterly over the southern half of the NWES (Fig. 3a). Toward the northwest of the domain, winter $\Delta$ SWSA decreases in magnitude and becomes southeasterly. The historical mean winter wind stress anomalies are predominantly southwesterly over the NWES (see supplemental Fig. 5 for historical and future SWSAs). Therefore, Fig. 3a indicates that winter wind stress anomalies will become more strongly southwesterly in the future over the Celtic Sea, the Irish Sea, the English Channel, and most of the North Sea. In contrast, summer $\Delta$ SWSA is approximately east-northeasterly (Fig. 3c), which indicates that the historical, predominantly north- 
(a)
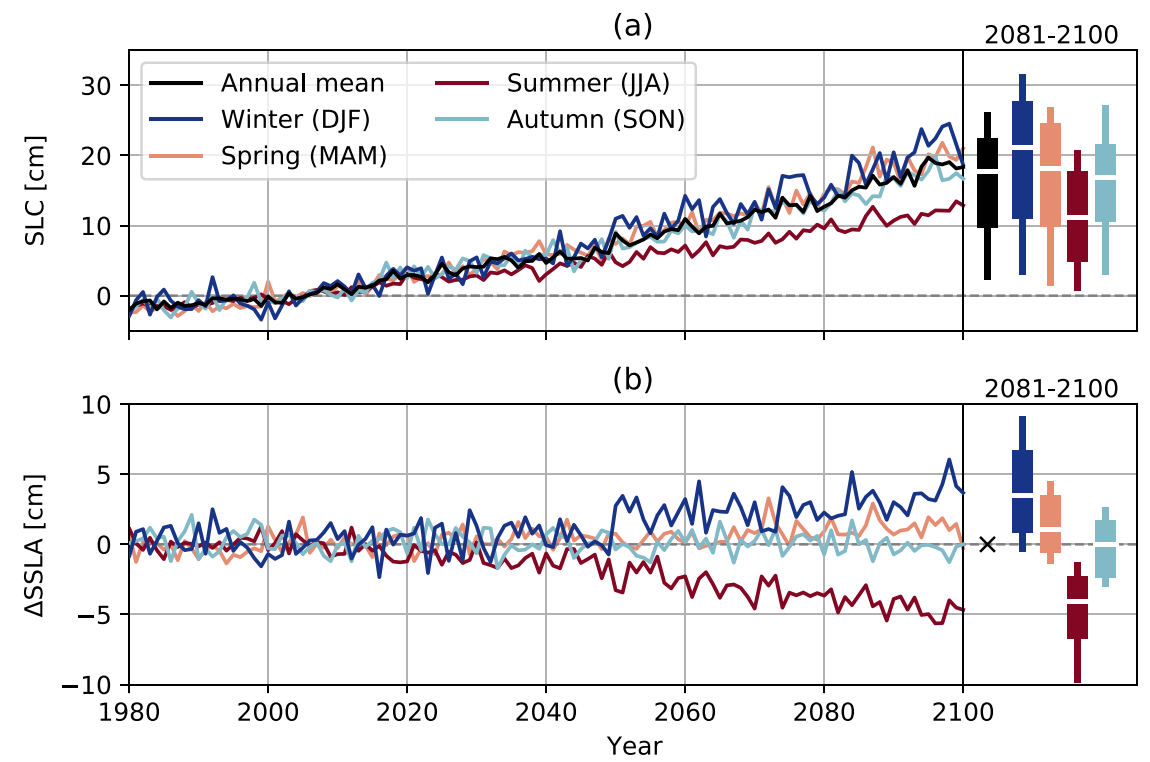

FIG. 2. Ensemble median projections for Esbjerg of (a) annual mean and seasonal mean DSLC $(\mathrm{cm})$ and of (b) the change in seasonal sea level anomalies $(\mathrm{cm})$ for SSP5-8.5 (relative to 1995-2014). The bars on the right indicate the $50 \%$ (horizontal white stripes), $17 \%-83 \%$ (thick bars), and $5 \%-95 \%$ (thin bars) percentiles of the multimodel distributions of the mean change in 2081-2100.

northeasterly wind stress anomalies over the NWES in summer will become more strongly northeasterly. Spring $\triangle$ SWSA varies from northerly to westerly over the North Sea (Fig. 3b) and autumn $\triangle$ SWSA is mainly southwesterly over the north and northwest of the NWES (Fig. 3d). Over most of the NWES, spring and autumn $\triangle$ SWSA are lower in magnitude than winter and summer $\Delta$ SWSA. Ensemble mean $\Delta$ SWSA differs relatively little from seasonal mean wind stress change because the annual mean wind stress change is relatively small over the NWES (supplemental Fig. 1b).

For a southwesterly wind stress increase over the NWES as in Fig. 3a, Ekman transport is expected to enhance sea level along the coasts to the right of the wind stress. Pingree and Griffiths (1980) modeled the effect of a spatially uniform southwesterly wind stress over the NWES and indeed found enhanced sea level in the English Channel, west of the United Kingdom, around Scotland and Norway, and particularly in the southeastern North Sea (their Fig. 3). This is qualitatively very similar to the ensemble mean winter $\Delta$ SSLA (Fig. 1a). Pingree and Griffiths (1980) also found that the increased sea level gradients perpendicular to the coast are accompanied by geostrophic changes in barotropic transport along the coast (their Fig. 2).

Assuming linearity, the response to a northeasterly wind stress change is approximately opposite to the response to a southwesterly wind stress change. This is consistent with the ensemble mean summer $\triangle$ SSLA (Fig. 1c), which is negative in the regions where winter $\triangle$ SSLA is positive (Fig. 1a). These patterns strongly suggest that the ensemble mean southwesterly and (east-)northeasterly winter and summer $\Delta$ SWSA over the shelf cause a large part of the winter and summer $\triangle$ SSLA, respectively. Basic scaling relationships between wind stress change and sea level change based on Ekman transport are likely not easily applicable here, since $\Delta$ SWSA is spatially nonuniform and involves changes in both magnitude and direction. Nevertheless, summer $\triangle$ SSLA is likely larger than winter $\Delta$ SSLA (Figs. 1a,c,e) because summer $\Delta$ SWSA is generally larger in magnitude than winter $\Delta$ SWSA (Figs. 3a,c). A dynamical effect similar to the projected change can be found in observations of SSLAs in years with approximately southwesterly and northeasterly SWSAs (supplemental Fig. 6).

The nearly shelf-wide positive and negative $\Delta$ SSLA in spring and autumn (Figs. 1b,d) cannot be reconciled with the Ekman transport expected for the relatively small northwesterly and southwesterly spring and autumn $\Delta$ SWSA (Figs. 3b,d), respectively. Instead, spring and autumn $\triangle$ SSLA may be more strongly affected by steric changes and mass redistribution between the shelf and the deep ocean than winter and summer $\Delta$ SSLA, since in the Northern Hemisphere the thermosteric component of the seasonal sea level cycle has a minimum in spring and a maximum in autumn (Tsimplis and Woodworth 1994; Vinogradov et al. 2008). We leave further investigation of steric effects on seasonal differences in DSLC to future work.

\section{b. The effect of $\triangle S W S A$ on $\triangle S S L A$ in individual CMIP6 models}

In winter and summer, the ensemble mean $\triangle$ SSLA and $\Delta$ SWSA appear dynamically consistent (section 4a). However, Figs. 1e and 2 reveal considerable intermodel differences in $\Delta$ SSLA. To understand the effect of the intermodel differences in $\triangle$ SWSA on the intermodel differences in $\triangle$ SSLA, we compare winter and summer $\Delta$ SWSA and $\Delta$ SSLA between three example CMIP6 models: CanESM5, UKESM1-0-LL, and IPSL-CM6A- 
(a) Winter (DJF)

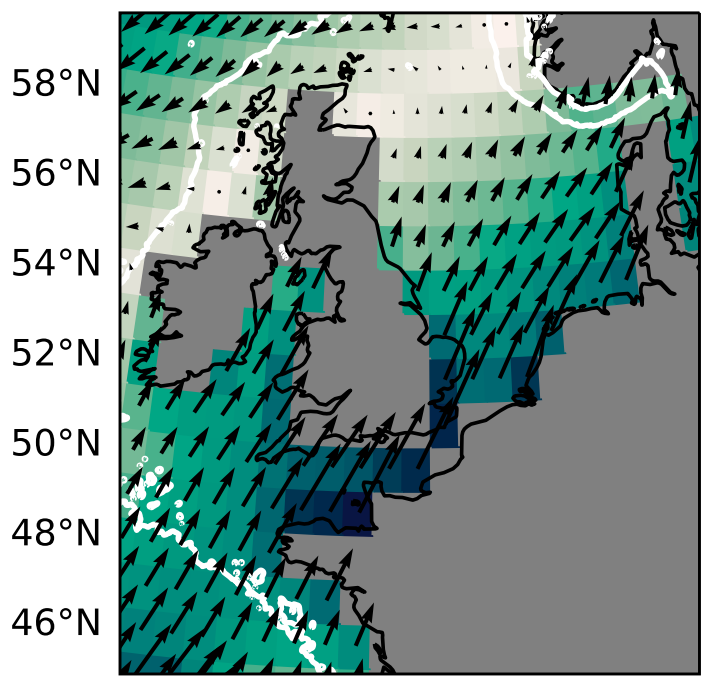

(c) Summer (JJA)

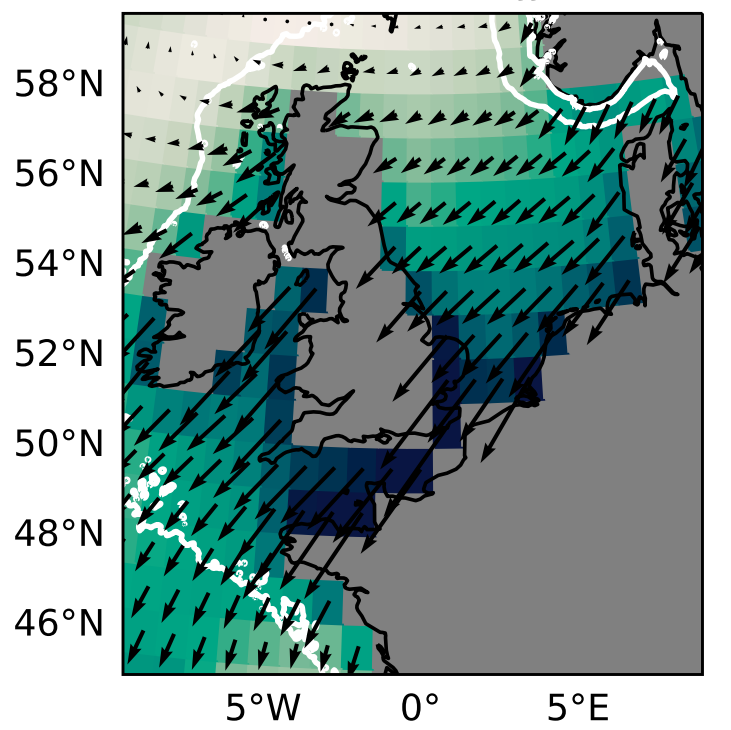

(b) Spring (MAM)

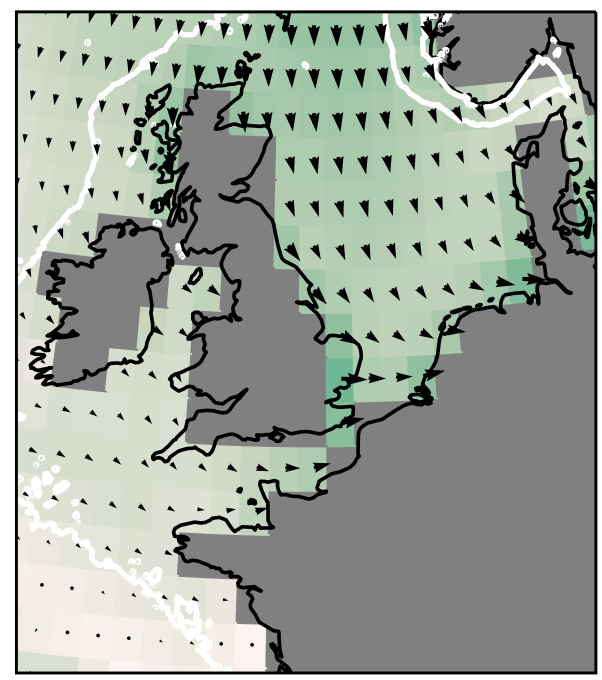

(d) Autumn (SON)

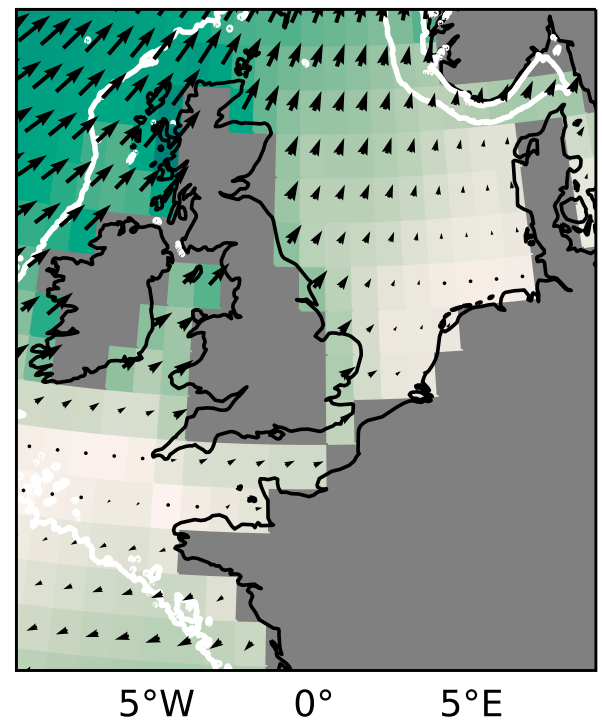

$0.02 \mathrm{~N} / \mathrm{m}^{2}$

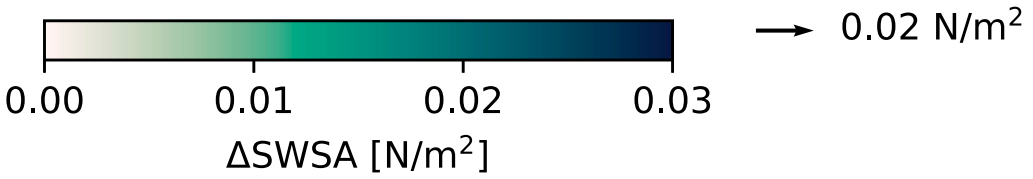

FIG. 3. Ensemble mean changes of (a) winter (DJF), (b) spring (MAM), (c) summer (JJA), and (d) autumn (SON) wind stress anomalies $\left(\mathrm{N} \mathrm{m}^{-2}\right)$ for SSP5-8.5 (2081-2100 relative to 1995-2014). The colors represent the absolute change and the arrows the direction. White contours and land masks as in Fig. 1.

LR. Additionally, as described in section 2b, we use our ROMS model to test the effect of the wind changes in these models on sea level and barotropic currents.

Winter and summer $\triangle$ SSLA vary in magnitude between CanESM5, UKESM1-0-LL, and IPSL-CM6A-LR (Figs. 4a-f, colors), but all three models resemble the ensemble mean spatial patterns (Figs. 1a,c). The $\Delta$ SWSA is also model-dependent and generally not spatially uniform over the region (Figs. 4a-f, arrows). Nevertheless, $\Delta$ SWSA and $\Delta$ SSLA appear to be consistent in the models: the stronger and more southwesterly or northeasterly the $\Delta$ SWSA over the region, the higher the magnitude of winter and summer $\Delta$ SSLA. The contrast between the over-ocean and overland $\Delta$ SWSA may be caused by the different surface roughness characteristics of the ocean and the 
(a) CanESM5 $(n=25)$

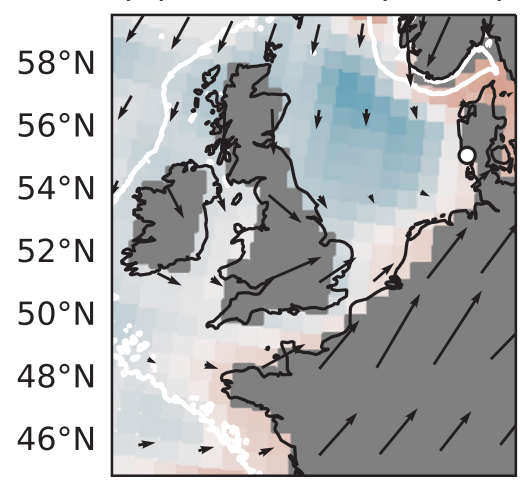

(d) CanESM5 $(n=25)$

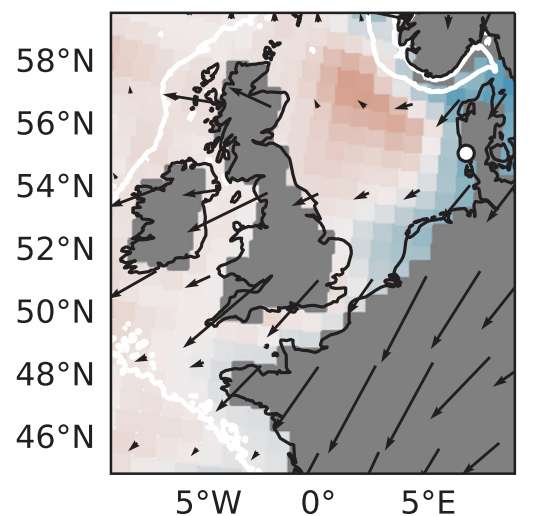

(b) UKESM1-0-LL $(n=5)$

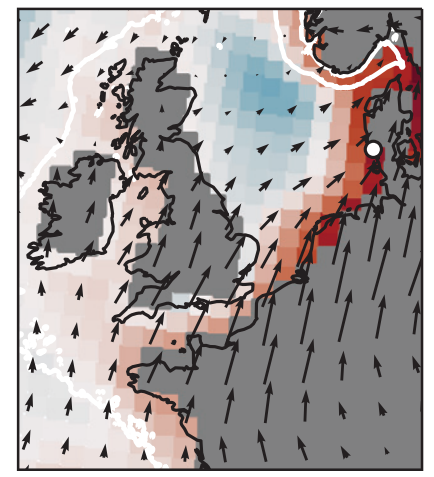

(e) UKESM1-0-LL $(n=5)$

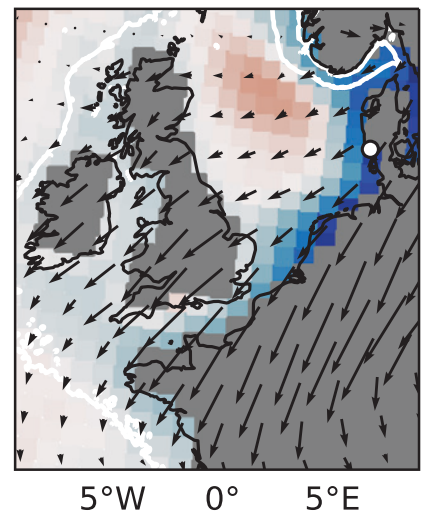

(c) IPSL-CM6A-LR $(\mathrm{n}=6)$

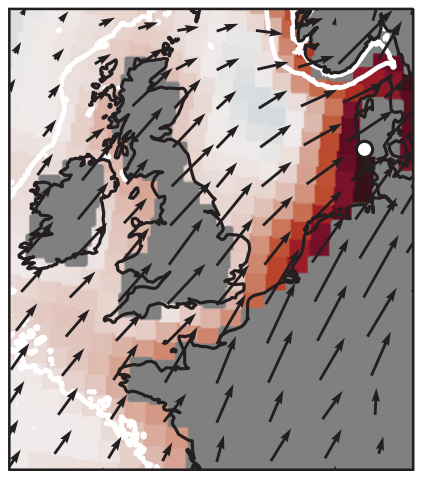

(f) IPSL-CM6A-LR $(\mathrm{n}=6)$

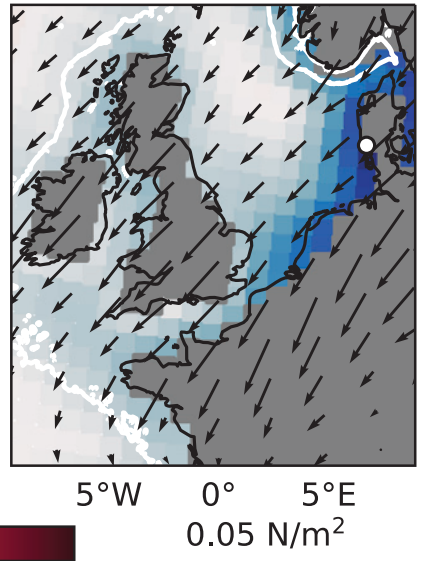

10 (g) CanESM5 $(n=25)$

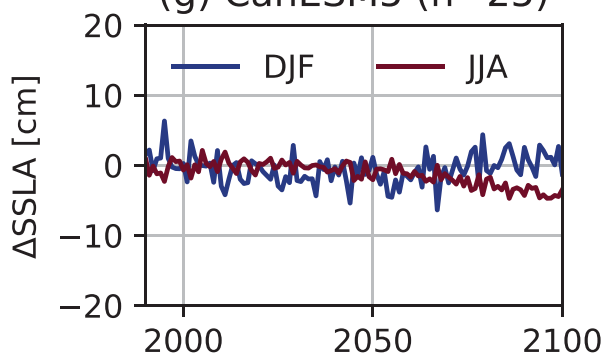

(h) UKESM1-0-LL $(n=5)$

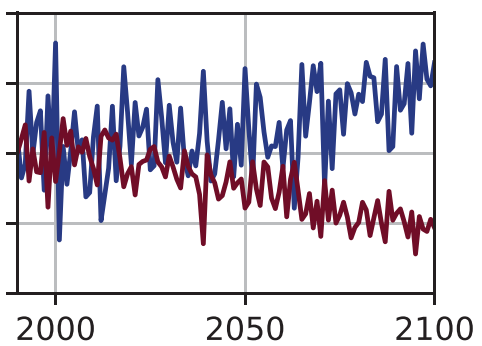

(i) IPSL-CM6A-LR $(n=6)$

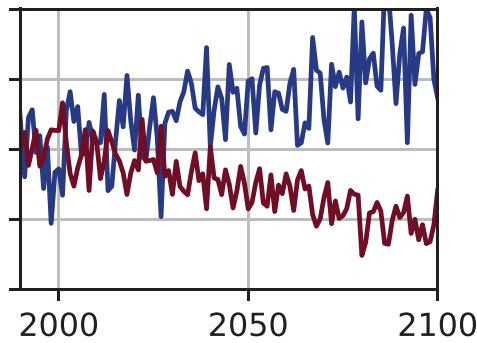

FIG. 4. Composite plots of changes in (top) winter (DJF) and (middle) summer (JJA) sea level anomalies (colors; cm) and wind stress anomalies (arrows; $\mathrm{N} \mathrm{m}^{-2}$ ) for (a),(d) CanESM5, (b),(e) UKESM1-0-LL, and (c),(f) IPSL-CM6A-LR for SSP5-8.5 (2081-2100 relative to 1995-2014); and (bottom) time series of winter (blue) and summer (red) sea level anomalies (cm) at Esbjerg for (g) CanESM5, (h) UKESM10-LL, and (i) IPSL-CM6A-LR. The number of realizations used for each model is indicated in the title of each panel. For (a)-(f), model specific grids are used (detailed in supplemental Table 1). The white circle in (a)-(f) denotes Esbjerg. White contours as in Fig. 1.

land, affecting the translation of wind-velocity changes to wind stress changes. The time series of $\triangle$ SSLA at Esbjerg reflect the model-dependent magnitudes of winter and summer $\triangle$ SSLA (Figs. 4g-i). Although less of the internal variability is averaged out for UKESM1-0-LL and IPSL-CM6A-LR (5 and 6 realizations) than for CanESM5 (25 realizations), Figs. 4g-i suggest that the projected changes in Fig. 4a-f mostly represent forced responses rather than multidecadal variability.
Next, we test the effect of winter and summer $\Delta$ SWSA in CanESM5, UKESM1-0-LL and IPSL-CM6A-LR on $\triangle$ SSLA by imposing the $\triangle$ SWVA derived from these models on the ROMS model (as explained in section $2 \mathrm{~b}$ ). The patterns of DSLC that the ROMS model simulates as a result (Fig. 5, colors) are very similar to the patterns of winter and summer $\triangle$ SSLA in the CMIP6 models (Fig. 4, colors). This confirms a causal relationship between $\triangle$ SWSA and $\triangle$ SSLA in winter 
(a) Exp_CAN, DJF

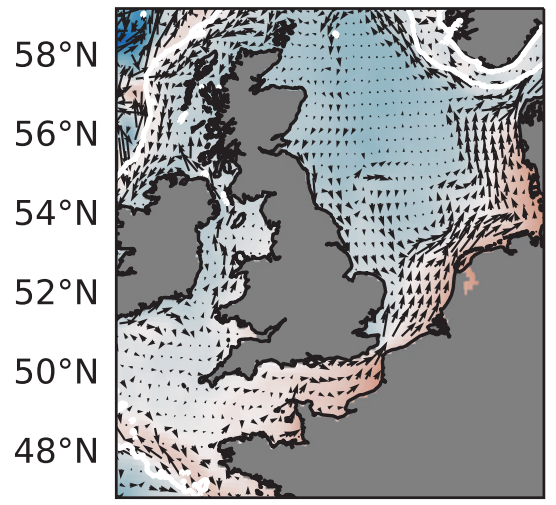

(d) Exp_CAN, JJA

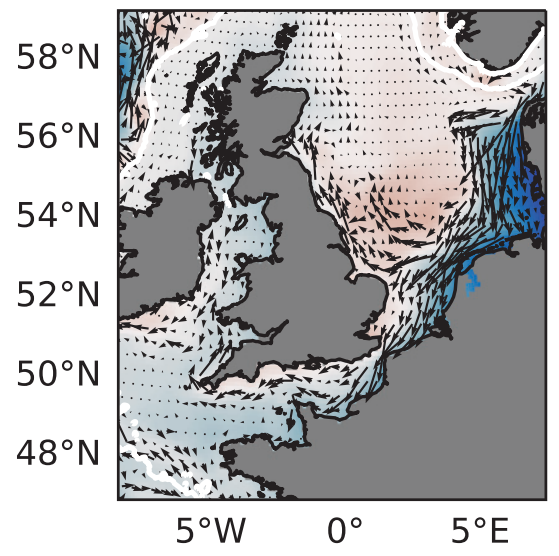

(b) Exp_UK, DJF

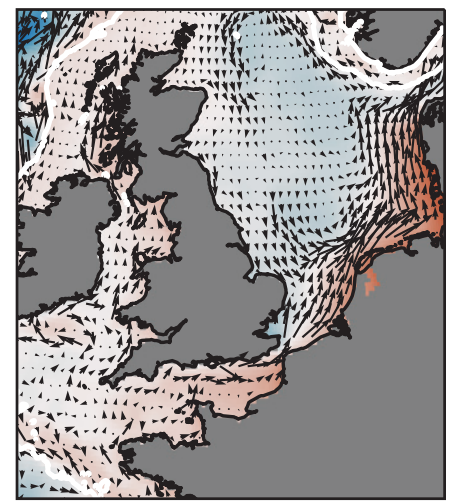

(e) Exp_UK, JJA

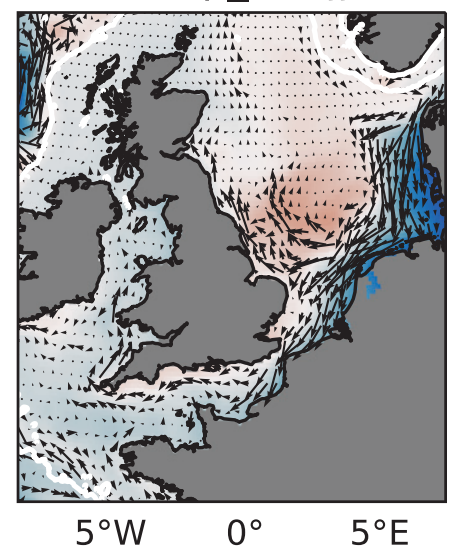

(c) Exp_IPSL, DJF

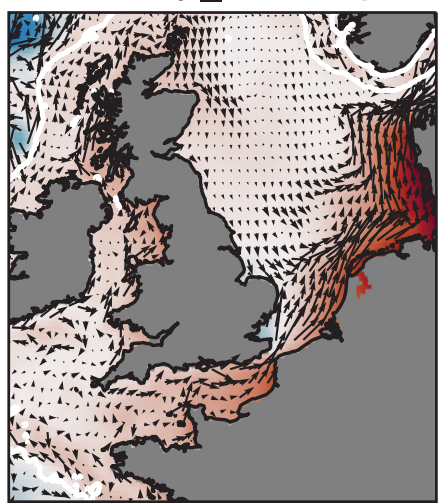

(f) Exp IPSL, JJA

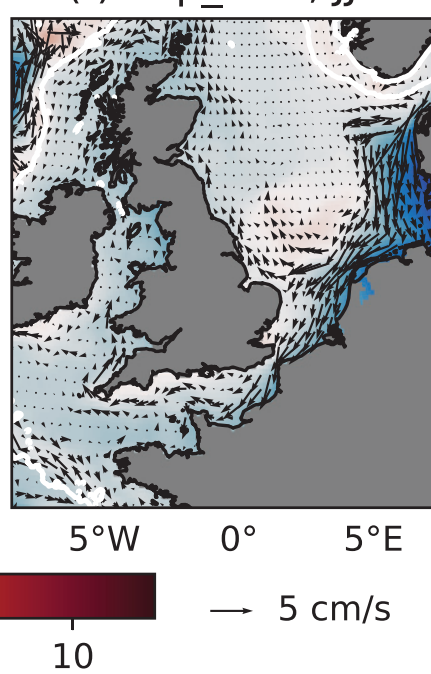

Sea-level response $[\mathrm{cm}]$

FIG. 5. Composite plots of the response of sea level (colors; $\mathrm{cm}$ ) and barotropic currents (arrows; $\mathrm{cm} \mathrm{s}^{-1}$ ) in ROMS to (top) winter and (bottom) summer $\triangle$ SWVA derived from (a),(d) CanESM5 (Exp_CAN), (b),(e) UKESM1-0-LL (Exp_UK), and (c),(f) IPSL-CM6A-LR (Exp_IPSL), relative to Exp_Ref (Table 1). The arrows representing the response of barotropic currents are plotted every ninth grid cell. White contours are as in Fig. 1.

and summer. Additionally, the model experiments imply that the $\triangle$ SSLA in the CMIP6 models are accompanied by changes in barotropic currents with opposite directions in winter and summer. For the experiments forced with winter $\triangle$ SWVA (Figs. 5a-c), DSLC is smallest in Exp_Can, intermediate in Exp_UK, and largest in Exp_IPSL. This is consistent with the winter $\triangle$ SSLA in the CMIP6 models (Figs. 4a-c) and suggests that the intermodel differences in $\triangle$ SWSA are responsible for the intermodel differences in $\triangle$ SSLA. For the experiments forced with summer $\triangle$ SWVA (Figs. 5d-f), however, DSLC in Exp_Can and Exp_UK are very similar despite the differences in summer $\triangle$ SWSA and $\triangle$ SSLA between CanESM5 and UKESM1-0-LL (Figs. 4d,e). This may reflect that other factors besides regional $\triangle$ SWSA affect winter and summer $\triangle$ SSLA in the CMIP6 models. It may also reflect differences in the translation of $\triangle$ SWVA to $\triangle$ SWSA between CanESM5 and UKESM1-0-LL due to differences in atmosphere-ocean coupling and the different atmosphere grid resolutions (supplemental Table 1).

The ensemble mean winter and summer $\triangle$ SSLA have a dipole pattern in the North Sea (Figs. 1a,c). This is likely caused by the wind-driven redistribution of mass in the North Sea: the ensemble mean winter and summer $\Delta$ SWSA both have a southeast to northwest gradient in magnitude and direction (Figs. 3a,c), which may respectively drive a divergence and convergence of the flow in the central and northern North Sea. For IPSL-CM6A-LR, the dipole pattern of $\Delta$ SSLA in the North Sea is less apparent (Figs. 4c,f). This appears to be consistent with the $\triangle$ SWSA in IPSL-CM6ALR, which is spatially more uniform than in the other models (Fig. 4). The absence of a dipole pattern in the sea level responses to a spatially uniform increase in southwesterly and northeasterly wind stress supports this interpretation (Exp_SW and Exp_NE; Fig. 6). The results of Exp_SW are 


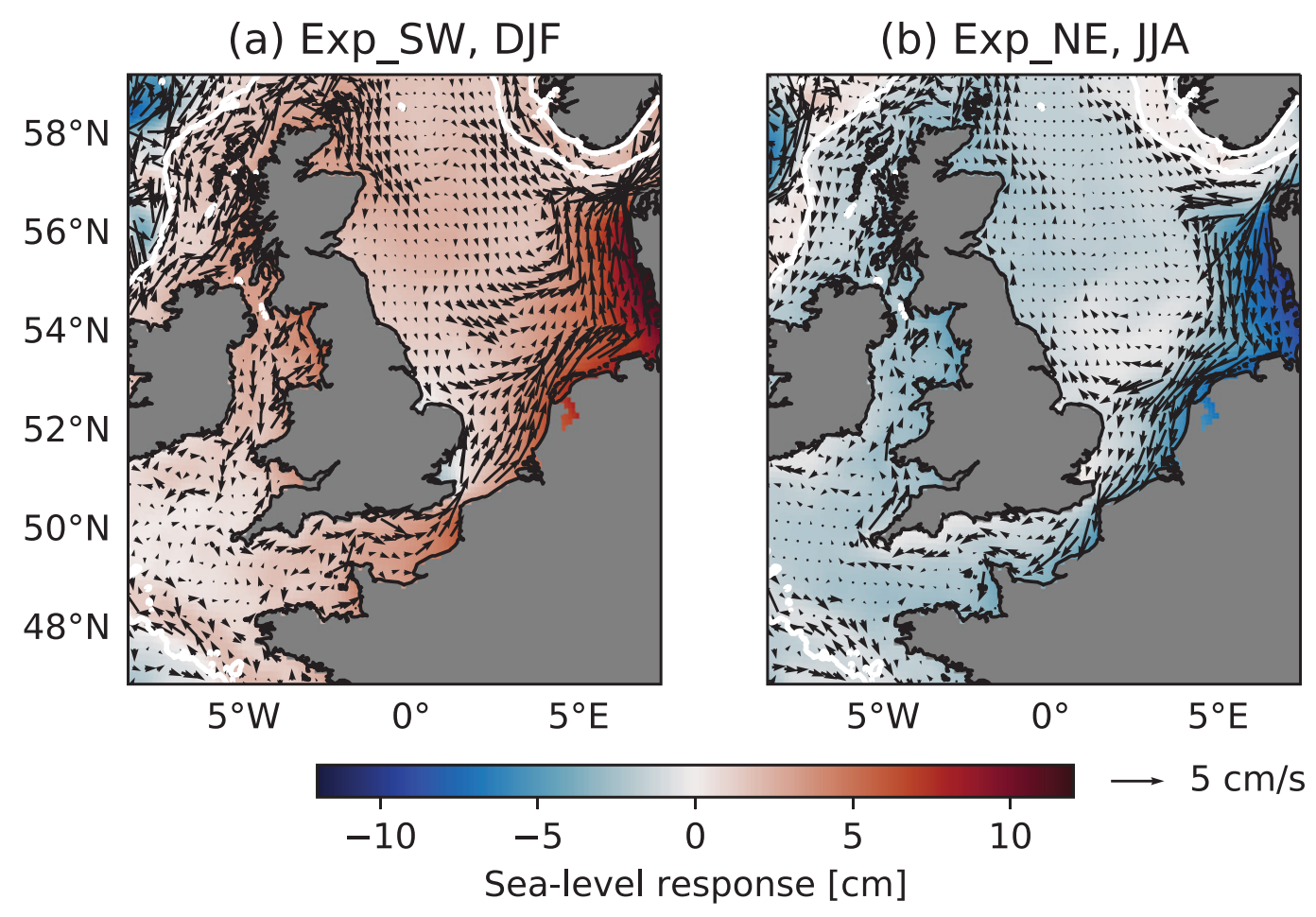

FIG. 6. Composite plots of the response of sea level (colors; $\mathrm{cm}$ ) and barotropic currents (arrows; $\mathrm{cm} \mathrm{s}^{-1}$ ) in ROMS in (a) Exp_SW in summer and (b) Exp_NE in winter, relative to Exp_Ref (Table 1). Arrows as in Fig. 5; white contours as in Fig. 1.

qualitatively very similar to the results of Pingree and Griffiths (1980, their Figs. 2 and 3).

\section{c. The effect of a closed English Channel on simulated $\triangle S S L A$}

Figures $6 \mathrm{a}$ and $6 \mathrm{~b}$ show that increased southwesterly and northeasterly wind stress over the NWES induce changes in barotropic transport through the English Channel. However, the native land masks of at least 8 of the 33 CMIP6 models in our ensemble (see supplemental Table 1) are too coarse to allow these models to resolve currents through the English Channel. Therefore, we adjust the land mask of the ROMS model to test the effect of closing the English Channel at the Strait of Dover on the results of Exp_SW and Exp_NW (Exp_SW_cc and Exp_NE_cc; Fig. 7).

With a closed English Channel, the effect of a southwesterly wind stress increase on sea level rise in winter is reduced in the southern and eastern North Sea and enhanced elsewhere on the NWES, especially along the southern and western coastline of the United Kingdom (Figs. 7a,c). The effect of a closed English Channel on the response to a northeasterly wind stress increase in summer is similar to some extent (Figs. 7b,d). That is, the sea level fall in summer is mainly reduced in the southern and eastern North Sea and enhanced along the southern and western U.K. coastline, but also somewhat reduced in the Celtic Sea. Since direct transport of water between the English Channel and the southern North Sea is blocked in Exp_SW_cc and
Exp_NE_cc, the response of barotropic currents to wind stress is reduced in the southern and eastern North Sea and enhanced on other parts of the shelf. Based on the results of these idealized experiments, we expect CMIP6 models with a closed English Channel to underestimate the difference between winter and summer DSLC in the southern and eastern North Sea and to overestimate it mainly along the coast of the United Kingdom.

We illustrate the effect of a closed English Channel for the CMIP6 model ACCESS-ESM1-5 by applying the winter $\triangle$ SWVA derived from ACCESS-ESM1-5 to our ROMS model (Fig. 8). When the English Channel is closed in the ROMS model, the sea level response is very similar to the winter $\triangle$ SSLA simulated by ACCESS-ESM1-5 itself (cf. Figs. $8 \mathrm{a}$ and $8 \mathrm{~b}$ ). When the English Chanel is open in the ROMS model, the sea level response is higher in the southeastern North Sea and lower around the United Kingdom than in ACCESS-ESM1-5 (cf. Figs. 8a and 8c). So, the representation of the English Channel in CMIP6 models affects their simulation of $\triangle$ SSLA on the NWES. Excluding CMIP6 models with a closed English Channel from the ensemble increases the ensemble mean of winter $\triangle$ SSLA at Den Helder by $0.6 \mathrm{~cm}(28 \%)$.

\section{Discussion and conclusions}

Sea level projections typically only consider annual mean RSLC, even though seasonal differences in DSLC may 


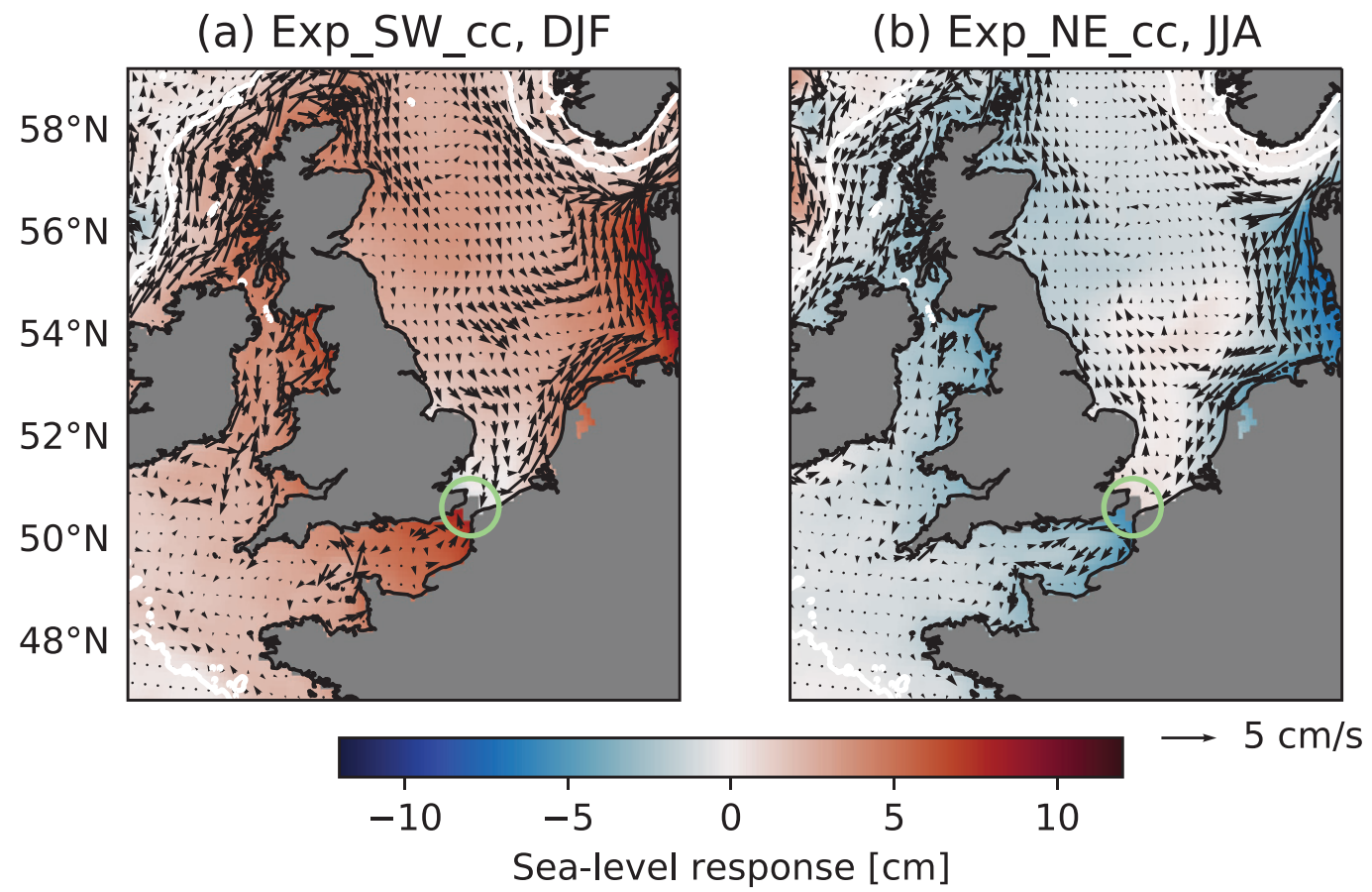

(c) Closed minus open

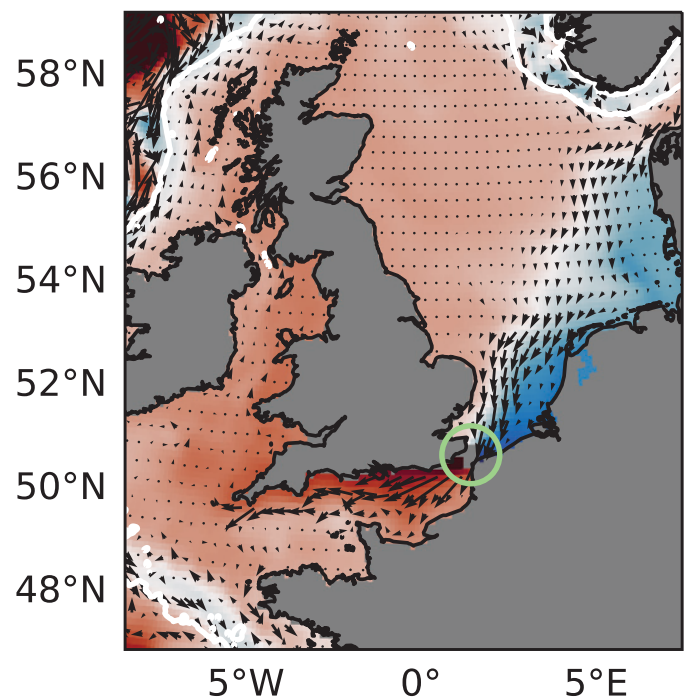

(d) Closed minus open

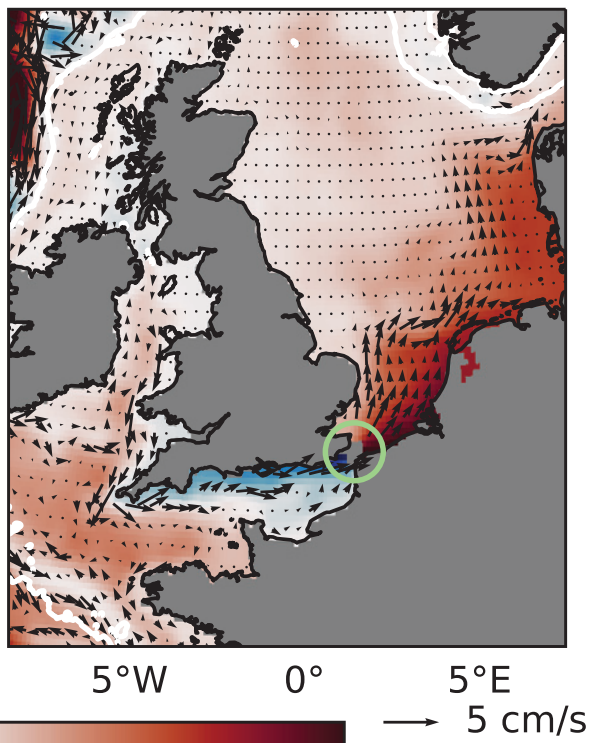

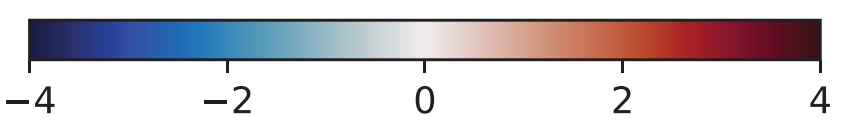

Sea-level difference $[\mathrm{cm}]$

FIG. 7. Composite plots of the response of sea level (colors; $\mathrm{cm}$ ) and barotropic currents (arrows; $\mathrm{cm} \mathrm{s}^{-1}$ ) in ROMS in (a) Exp_SW_cc in summer and (b) Exp_NE_cc in winter, relative to Exp_Ref_cc (Table 1). (c),(d) Results in (a) and (b) minus those in Figs. 6a and 6b (response with a closed English Channel minus with an open English Channel). Arrows as in Fig. 5; white contours as in Fig. 1. The green circles indicate the closed English Channel in the modified land mask.

modulate the impacts of annual mean RSLC. Therefore, we studied the seasonal differences in DSLC on the NWES and investigated their causes. Based on an ensemble of 33 CMIP6 models, we find substantial changes in seasonal sea level anomalies on the NWES for the SSP5-8.5 scenario, indicating substantial seasonal differences in DSLC. The seasonality of 
(a) ACCESS-ESM1-5

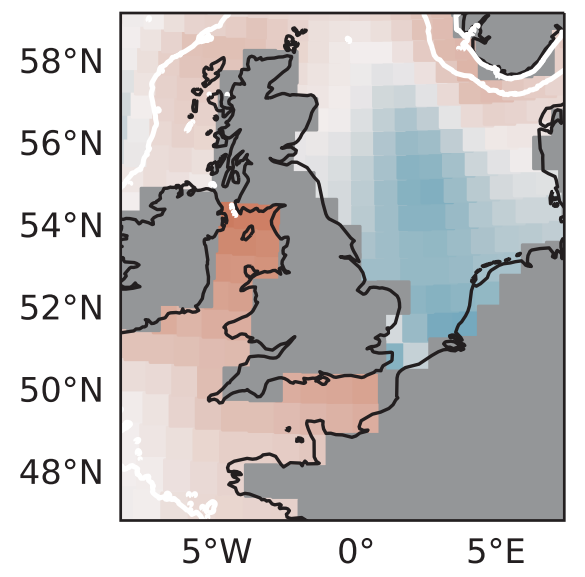

(b) Exp_ACC_cC

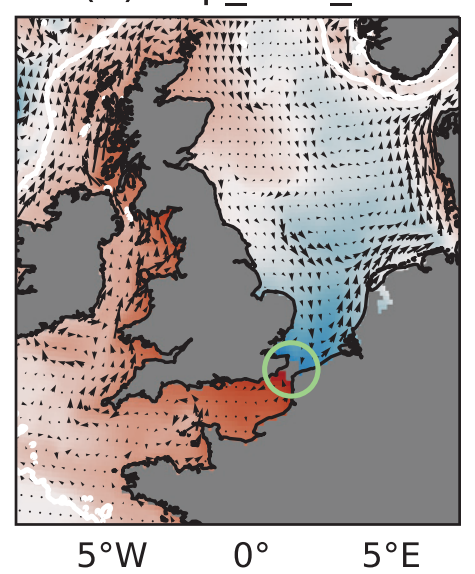

(c) Exp_ACC

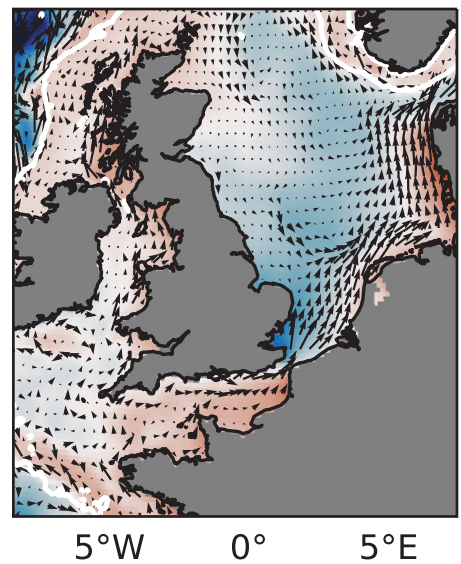

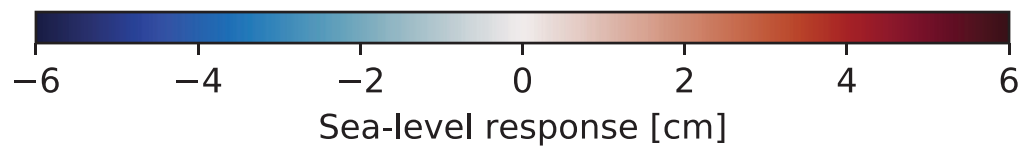

$\rightarrow 5 \mathrm{~cm} / \mathrm{s}$

FIG. 8. (a) Winter $\Delta$ SSLA (cm) simulated by ACCESS-ESM1-5 for SSP5-8.5 (2081-2100 relative to 1995-2014). Also shown are composite plots of the response of sea level (colors; $\mathrm{cm}$ ) and barotropic currents (arrows; $\mathrm{m} \mathrm{s}^{-1}$ ) in ROMS to winter $\Delta$ SWVA derived from ACCESS-ESM1-5, with (b) a closed English Channel (Exp_ACC_cc relative to Exp_Ref_cc) and (c) an open English Channel (Exp_ACC relative to Exp_Ref) (Table 1). Arrows as in Fig. 5; white contours as in Fig. 1; green circles as in Fig. 7.

DSLC is largest in the southeastern North Sea, where sea level rises most in winter and least in summer (Fig. 1). Our experiments with a regional ocean model indicate that the differences between winter and summer mean DSLC are for a large part caused by the differences in regional wind stress change between these seasons (section 4). For SSP1-2.6, seasonal differences in DSLC are much smaller, because atmospheric circulation changes are weaker for lower emissions scenarios (Collins et al. 2013).

To our knowledge, only one other study has investigated seasonal sea level projections on the NWES using a multimodel ensemble (Dangendorf et al. 2014b). Although limited to the German Bight, Dangendorf et al. (2014b) found that the ensemble mean sea level rise of eight CMIP3 models was largest in winter and smallest in spring and summer. This partially agrees with our results, but we also find relatively large sea level rise in spring (Fig. 1b). The seasonal projections of Dangendorf et al. (2014b) were based on a sea level pressure proxy reflecting the correlation between sea level and local zonal wind stress. In contrast, we find that the twenty-first-century changes in winter and summer sea level anomalies are mainly caused by regional southwesterly and east-northeasterly wind stress changes. The sea level response is most likely governed by Ekman transport and accompanied by changes in barotropic transport on the shelf. The proxy of Dangendorf et al. (2014b) does not fully capture these regional dynamics, nor does it account for steric effects, which may influence $\Delta$ SSLA especially in spring and autumn (section 4a).

Since we find that the changes in winter and summer sea level anomalies on the NWES are largely driven by regional changes in wind stress anomalies, the large intermodel spread of projections of atmospheric circulation change (e.g., Oudar et al. 2020; Shepherd 2014; Woollings 2010) likely introduces substantial uncertainty in projected $\Delta$ SSLA (e.g., Figs. 1, 2, and 4 ). It may be possible to constrain projections of $\triangle$ SSLA by weighting the CMIP6 models according to their performance and interdependence in simulating historical sea level or wind stress (e.g., Knutti et al. 2017; Lyu et al. 2020). Studies evaluating the seasonal sea level cycle on the NWES in CMIP6 models are currently lacking, but they would be warranted in light of our results. Another part of the intermodel spread stems from internal variability, associated with the limited number of realizations available for some of the CMIP6 models. Although quantifying this uncertainty would require additional realizations, the differences between our projections of $\triangle$ SSLA and those derived by using only a single realization per model (supplemental Fig. 7) suggest that the ensemble uncertainty due to internal variability is relatively modest.

While we focused on future changes and did not evaluate historical performance in this manuscript, we do find that nearly $25 \%$ of the CMIP6 models in our ensemble do not resolve the currents through the English Channel (supplemental Table 1). This leads to an underestimation of seasonal differences in DSLC in the southern and eastern North Sea and an overestimation mainly along the southern and western coastline of the United Kingdom (section 4c). Not resolving currents through the English Channel likely affects simulations of annual mean DSLC as well (Hermans et al. 2020b). Therefore, we advocate excluding models that do not resolve currents through the English Channel when projecting DSLC for the NWES, unless 
the model simulations are dynamically downscaled first. Other resolution issues, such as related to resolving the inflow of the North Atlantic Current into the northern North Sea and the wind forcing near the coast, may further impact the CMIP6 simulations of $\triangle$ SSLA and need to be investigated.

We studied seasonal differences in DSLC for SSP5-8.5 and SSP1-2.6, and focused on the effect of wind stress change to explain these. As a next step, results for SSP scenarios in between SSP5-8.5 and SSP1-2.6 could be further investigated. Since changes in wind stress are coupled to changes in sea level pressure, investigating the additional seasonal differences in DSLC that the inverse barometer effect (Stammer and Hütteman 2008) may introduce would also be useful. Additionally, follow-up studies could investigate steric effects in more detail by partitioning seasonal differences in DSLC into steric and manometric changes.

We see two potentially important implications of the seasonal differences in DSLC that we found. First, flood risk assessments and adaptation planning are currently based on projections of annual mean RSLC (e.g., Oppenheimer et al. 2019). We showed that coastal sea level rise on the NWES exceeds the annual mean in spring and winter, which may cause a stronger shift in the distribution of extreme sea levels in these seasons than currently considered. Whether the increase in winter sea level anomalies, which is mainly caused by increased southwesterly wind stress, can be superimposed on the height of the most severe storm surges in the southeastern North Sea, which occur for extreme northwesterly and westerly winds (de Winter et al. 2013; Sterl et al. 2009), is not yet clear. Second, mainly in the southeastern North Sea, the seasonal differences in DSLC imply a shift in the phase and an increase in the amplitude of the seasonal sea level cycle (e.g., supplemental Fig. 2i). This may impact coastal groundwater dynamics (Gonneea et al. 2013) and ecosystems in the intertidal zone. Whereas salt marshes with sufficient sediment accretion may keep up with centennial sea level rise (Kirwan et al. 2016), even small changes in the seasonal sea level cycle have the potential to significantly change the seasonal inundation characteristics of intertidal ecosystems, affecting the prospects for salt marsh development (Balke et al. 2016; Kim et al. 2011; Morris 2000). Therefore, it is worth considering seasonal RSLC on the NWES and its impacts in addition to the annual mean change. This may apply to other regions as well.

Acknowledgments. This study has been conducted using E.U. Copernicus Marine Service information (provided in 2019). Neither the European Commission nor ECMWF is responsible for any use that may be made of the Copernicus Information or data it contains.

We acknowledge the WCRP, which, through its Working Group on Coupled Modeling, coordinated and promoted CMIP6. We thank the climate modeling groups for producing and making available their model output, the ESGF for archiving the data and providing access, and the multiple funding agencies who support CMIP6 and ESGF. We downloaded the CMIP6 simulations available in July 2021.
We thank Dewi Le Bars, Sybren Drijfhout, Rein Haarsma, Jim van Belzen, and Greg Fivash for the helpful discussions.

Data availability statement. The processed CMIP6 output and the output of the ROMS model experiments underlying our figures can be obtained from the 4TU.ResearchData repository: https://doi.org/10.4121/16831918. The code that we used to obtain, process, and analyze this data is available at Zenodo: https://doi.org/10.5281/zenodo.5654667.

\section{REFERENCES}

Amante, C., and B. W. Eakins, 2009: ETOPO1 1 arc-minute global relief model: Procedures, data sources, and analysis. NOAA Tech. Memo. NESDIS NGDC-24, 25 pp., https://www.ngdc. noaa.gov/mgg/global/relief/ETOPO1/docs/ETOPO1.pdf (dataset available at https://doi.org/10.7289/V5C8276M).

Balke, T., M. Stock, K. Jensen, T. J. Bouma, and M. Kleyer, 2016: A global analysis of the seaward salt marsh extent: The importance of tidal range. Water Resour. Res., 52, 3775-3786, https://doi.org/10.1002/2015WR018318.

CDS, 2019: ERA5 hourly data on single levels from 1979 to present. Copernicus Climate Data Store (CDS), accessed 15 October 2019, https://doi.org/10.24381/cds.adbb2d47.

Collins, M., and Coauthors, 2013: Long-term climate change: Projections, commitments and irreversibility. Climate Change 2013: The Physical Science Basis, T. F. Stocker et al., Eds., Cambridge University Press, 1029-1136.

Dai, A., 2017: Dai and Trenberth global river flow and continental discharge dataset. Research Data Archive at the National Center for Atmospheric Research, Computational and Information Systems Laboratory, accessed 24 October 2019, https://doi.org/10.5065/D6V69H1T.

Dangendorf, S., T. Wahl, H. Hein, J. Jensen, S. Mai, and C. Mudersbach, 2012: Mean sea level variability and influence of the North Atlantic Oscillation on long-term trends in the German Bight. Water, 4, 170-195, https://doi.org/10.3390/ w4010170.

— C. Mudersbach, T. Wahl, and J. Jensen, 2013a: Characteristics of intra-, inter-annual and decadal sea-level variability and the role of meteorological forcing: The long record of Cuxhaven. Ocean Dyn., 63, 209-224, https://doi.org/10.1007/ s10236-013-0598-0.

- T. Wahl, C. Mudersbach, and J. Jensen, 2013b: The seasonal mean sea level cycle in the southeastern North Sea. J. Coast. Res., 165, 1915-1920, https://doi.org/10.2112/SI65-324.1.

— , F. M. Calafat, A. Arns, T. Wahl, I. D. Haigh, and J. Jensen, 2014a: Mean sea level variability in the North Sea: Processes and implications. J. Geophys. Res. Oceans, 119, 6820-6841, https://doi.org/10.1002/2014JC009901.

— , T. Wahl, E. Nilson, B. Klein, and J. Jensen, 2014b: A new atmospheric proxy for sea level variability in the southeastern North Sea: Observations and future ensemble projections. Climate Dyn., 43, 447-467, https://doi.org/10.1007/s00382-0131932-4.

de Winter, R. C., A. Sterl, and B. G. Ruessink, 2013: Wind extremes in the North Sea Basin under climate change: An ensemble study of 12 CMIP5 GCMs. J. Geophys. Res. Atmos., 118, 1601-1612, https://doi.org/10.1002/jgrd.50147.

Ekman, M., 1998: Secular change of the seasonal sea level variation in the Baltic Sea and secular change of the winter 
climate. Geophysica, 34, 131-140, http://www.geophysica.fi/ pdf/geophysica_1998_34_3_131_ekman.pdf.

Eyring, V., and Coauthors, 2016: Overview of the Coupled Model Intercomparison Project Phase 6 (CMIP6) experimental design and organization. Geosci. Model Dev., 9, 1937-1958, https:/doi. org/10.5194/gmd-9-1937-2016.

— , and Coauthors, 2020: Earth System Model Evaluation Tool (ESMValTool) v2. 0-An extended set of large-scale diagnostics for quasi-operational and comprehensive evaluation of Earth system models in CMIP. Geosci. Model Dev., 13, 3383-3438, https://doi.org/10.5194/gmd-13-3383-2020.

Fox-Kemper, B., and Coauthors, 2021: Ocean, cryosphere and sea level change. Climate Change 2021: The Physical Science Basis, V. Masson-Delmotte et al., Eds., Cambridge University Press, in press.

Frederikse, T., and T. Gerkema, 2018: Multi-decadal variability in seasonal mean sea level along the North Sea coast. Ocean Sci., 14, 1491-1501, https://doi.org/10.5194/os-14-1491-2018.

Gerkema, T., and M. Duran-Matute, 2017: Interannual variability of mean sea level and its sensitivity to wind climate in an inter-tidal basin. Earth Syst. Dyn., 8, 1223-1235, https://doi. org/10.5194/esd-8-1223-2017.

Gonneea, M. E., A. E. Mulligan, and M. A. Charette, 2013: Climate-driven sea level anomalies modulate coastal groundwater dynamics and discharge. Geophys. Res. Lett., 40, 27012706, https://doi.org/10.1002/grl.50192.

Gregory, J. M., and Coauthors, 2019: Concepts and terminology for sea level: Mean variability and change, both local and global. Surv. Geophys., 40, 1251-1289, https://doi.org/10.1007/ s10712-019-09525-z.

Hermans, T. H. J., D. Le Bars, C. A. Katsman, C. M. L. Camargo, T. Gerkema, F. M. Calafat, J. Tinker, and A. B. A. Slangen, 2020a: Drivers of interannual sea level variability on the Northwestern European Shelf. J. Geophys. Res. Oceans, 125, e2020JC016325, https://doi.org/10.1029/2020JC016325.

—, J. Tinker, M. D. Palmer, C. A. Katsman, B. L. A. Vermeersen, and A. B. A. Slangen, 2020b: Improving sea-level projections on the Northwestern European Shelf using dynamical downscaling. Climate Dyn., 54, 1987-2011, https:// doi.org/10.1007/s00382-019-05104-5.

Hinkel, J., and Coauthors, 2019: Meeting user needs for sea level rise information: A decision analysis perspective. Earth's Future, 7, 320-337, https://doi.org/10.1029/2018EF001071.

Hobbs, W., M. D. Palmer, and D. Monselesan, 2016: An energy conservation analysis of ocean drift in the CMIP5 global coupled models. J. Climate, 29, 1639-1653, https://doi.org/10. 1175/JCLI-D-15-0477.1.

Kara, A. B., A. J. Wallcraft, and H. E. Hurlburt, 2007: A correction for land contamination of atmospheric variables near land-sea boundaries. J. Phys. Oceanogr., 37, 803-818, https:// doi.org/10.1175/JPO2984.1.

Kim, D., D. M. Cairns, J. Bartholdy, D. Kim, D. M. Cairns, and J. Bartholdy, 2011: Wind-driven sea-level variation influences dynamics of salt marsh vegetation. Ann. Assoc. Amer. Geogr., 101, 231-248, https://doi.org/10.1080/00045608.2010.544933.

Kirwan, M., S. Temmerman, E. Skeehan, G. Guntenspergen, and S. Fagherazzi, 2016: Overestimation of marsh vulnerability to sea level rise. Nat. Climate Change, 6, 253-260, https://doi. org/10.1038/nclimate2909.

Knutti, R., J. Sedlacek, B. M. Sanderson, R. Lorenz, E. M. Fischer, and V. Eyring, 2017: A climate model projection weighting scheme accounting for performance and interdependence.
Geophys. Res. Lett., 44, 1909-1918, https://doi.org/10.1002/ 2016 GL072012.

Lellouche, J., and Coauthors, 2018: Recent updates to the Copernicus Marine Service global ocean monitoring and forecasting real-time 1/12 high-resolution system. Ocean Sci., 14, 10931126, https://doi.org/10.5194/os-14-1093-2018.

Lyu, K., X. Zhang, and J. A. Church, 2020: Regional dynamic sea level simulated in the CMIP5 and CMIP6 models: Mean biases, future projections, and their linkages. J. Climate, 33, 6377-6398, https://doi.org/10.1175/JCLI-D-19-1029.1.

Marcos, M., and M. N. Tsimplis, 2007: Forcing of coastal sea level rise patterns in the North Atlantic and the Mediterranean Sea. Geophys. Res. Lett., 34, L18604, https://doi.org/10.1029/ 2007 GL030641.

Mathis, M., 2013: Projected forecast of hydrodynamic conditions in the North Sea for the 21st century. Doctoral dissertation, University of Hamburg, 177 pp., https://ediss.sub.uni-hamburg. de/handle/ediss/4905? mode=full.

Morris, J. T., 2000: Effects of sea level anomalies on estuarine processes. Estuarine Science: A Synthetic Approach to Research and Practice, J. Hobbie, Ed., Island Press, 107-127.

O’Neill, B. C., E. Kriegler, K. Riahi, K. L. Ebi, S. Hallegatte, T. R. Carter, R. Mathur, and D. P. Van Vuuren, 2014: A new scenario framework for climate change research: The concept of shared socioeconomic pathways. Climatic Change, 122, 387-400, https://doi.org/10.1007/s10584-013-0905-2.

Oppenheimer, M., and Coauthors, 2019: Sea level rise and implications for low lying islands, coasts and communities. IPCC Special Report on the Ocean and Cryosphere in a Changing Climate, H.-O. Pörtner, Ed., IPCC.

Oudar, T., J. Cattiaux, and H. Douville 2020: Drivers of the northern extratropical eddy-driven jet change in CMIP5 and CMIP6 models. Geophys. Res. Lett., 47, e2019GL086695, https://doi.org/10.1029/2019GL086695.

Pingree, R. D., and D. K. Griffiths, 1980: Currents driven by a steady uniform wind stress on the shelf seas around the British Isles. Oceanol. Acta, 3, 227-236.

Plag, H., and M. N. Tsimplis, 1999: Temporal variability of the seasonal sea-level cycle in the North Sea and Baltic Sea in relation to climate variability. Global Planet. Change, 20, 173-203, https://doi.org/10.1016/S0921-8181(98)00069-1.

Roberts, C. D., D. Calvert, N. Dunstone, L. Hermanson, M. D. Palmer, and D. Smith, 2016: On the drivers and predictability of seasonal-to-interannual variations in regional sea level. $J$. Climate, 29, 7565-7585, https://doi.org/10.1175/JCLI-D-150886.1.

Sen Gupta, A., N. C. Jourdain, J. N. Brown, and D. Monselesan, 2013: Climate drift in CMIP5 models. J. Climate, 26, 8597 8615, https://doi.org/10.1175/JCLI-D-12-00521.1.

Shchepetkin, A. F., and J. C. McWillams, 2005: The regional oceanic modeling system (ROMS): A split-explicit, free-surface, topography-following-coordinate oceanic model. Ocean Modell., 9, 347-404, https://doi.org/10.1016/j.ocemod.2004.08.002.

Shepherd, T. G., 2014: Atmospheric circulation as a source of uncertainty in climate change projections. Nat. Geosci., 7, 703-708, https://doi.org/10.1038/ngeo2253.

Stammer, D., and S. Hüttemann, 2008: Response of regional sea level to atmospheric pressure loading in a climate change scenario. J. Climate, 21, 2093-2101, https://doi.org/ 10.1175/2007JCLI1803.1.

Sterl, A., H. van den Brink, H. de Vries, R. Haarsma, and E. van Meijgaard, 2009: An ensemble study of extreme storm surge 
related water levels in the North Sea in a changing climate. Ocean Sci., 5, 369-378, https://doi.org/10.5194/os-5-369-2009.

Tinker, J., M. D. Palmer, D. Copsey, T. Howard, J. A. Lowe, and T. H. J. Hermans, 2020: Dynamical downscaling of unforced interannual sea-level variability in the North-West European shelf seas. Climate Dyn., 55, 2207-2236, https://doi.org/10. 1007/s00382-020-05378-0.

Tsimplis, M. N., and P. L. Woodworth, 1994: The global distribution of the seasonal sea level cycle calculated from coastal tide gauge data. J. Geophys. Res., 99, 16031-16040, https:// doi.org/10.1029/94JC01115.

Vinogradov, S. V, R. M. Ponte, P. Heimbach, and C. Wunsch, 2008: The mean seasonal cycle in sea level estimated from a data-constrained general circulation model. J. Geophys. Res., 113, C03032, https://doi.org/10.1029/2007JC004496.
Vinogradova, N. T., R. M. Ponte, and D. Stammer, 2007: Relation between sea level and bottom pressure and the vertical dependence of oceanic variability. Geophys. Res. Lett., 34, L03608, https://doi.org/10.1029/2006GL028588.

Widlansky, M. J., X. Long, and F. Schloesser, 2020: Increase in sea level variability with ocean warming associated with the nonlinear thermal expansion of seawater. Commun. Earth Environ., 1, 9, https://doi.org/10.1038/s43247-020-0008-8.

Woollings, T., 2010: Dynamical influences on European climate: An uncertain future. Philos. Trans. Roy. Soc., A368, 3733-3756, https://doi.org/10.1098/rsta.2010.0040.

Yin, J., 2012: Century to multi-century sea level rise projections from CMIP5 models. Geophys. Res. Lett., 39, L17709, https:/ doi.org/10.1029/2012GL052947. 